\title{
Environmental aspects of the competitiveness strategy of mining enterprises in the context of sustainable development
}

\author{
Olha Popelo ${ }^{1}$, Viktoriia Marhasova ${ }^{1}$, Olga Garafonova $^{2}$, and Svetlana Grigashkina ${ }^{3}$ \\ ${ }^{1}$ Chernihiv Polytechnic National University, Chernihiv, 14035, Ukraine \\ ${ }^{2}$ Kyiv National Economics University named after Vadym Hetman, Kyiv, 03680, Ukraine \\ ${ }^{3}$ T.F. Gorbachev Kuzbass State Technical University, Kemerovo, 650000, Russia
}

\begin{abstract}
The article reveals the environmental aspects of the competitiveness strategies of mining enterprises in the context of ensuring sustainable development of the economy. The reasons as a result of which the state of the environment in the process of development of oil and gas fields worsens are investigated. The stages of search for exploration and development of oil and gas fields are considered. The negative impact on the environment component of sustainable development of prospecting and exploitation works on oil fields has been determined.
\end{abstract}

\section{Introduction}

In the context of sustainable economic development, mining companies need to form a competitiveness strategy that takes into account the environmental component as much as possible. The problem of ensuring environmental safety during the implementation of their activities by subsoil users in the process of mining is very acute.

The concept of environmental safety in the course of mining activities has a multifaceted nature and is not limited to ensuring the environmental safety of the geological environment. It should be noted that this concept is related to the environmental safety of land resources, air, groundwater.

In the context of ensuring the sustainable development of the economy of the regions, it is necessary to provide for geological and ecological explorations as part of a comprehensive study of the environment by subsoil users before the relevant work, which will contribute to comprehensive solutions to important problems.

\section{Literature review}

Many scientific works of domestic and foreign scientists are devoted to the issues of ecological safety of mining, the impact of subsoil use processes on sustainable development [1-16].

\footnotetext{
* Corresponding author: popelo.olha@gmail.com
} 
In a study by scientists Li Z., Zhou Y., Meng X. and Wang S. was synthesized environmentally friendly degreaser CYJ-1 with good degreasing performance in solid fatty waste, the degree of degreasing of which is $93 \%$. The results of the program show that the use of this technology can effectively solve the problems of environmental pollution and recovery of oil drilling fluid [7].

Scientists from Spain, Germany and Romania say that one of the measures to mitigate some of today's environmental problems is to produce products from renewable resources. According to the main results of the comparison of the four scenarios showed that the best scenario from the ecological point of view is the burning of agave-bagas followed by gasification of agave-bagas, gasification of sugar cane and burning of sugar cane [10].

Scientists Zakaria Z., Kamarudin S.K., Abd Wahid K.A. and Abu Hassan S.H. in their research note that global population growth has increased global energy demand. Unfortunately, traditional electricity generation in Malaysia is heavily dependent on natural gas, coal and oil. As a result, many environmental problems have arisen that harm the region [16].

Scientists Chew K.W., Chia S.R., Chia W.Y., Cheah W.Y., Munawaroch H.S. and Ong W.-J. point out that human progress has created various consequences in the form of polluted environment, accumulation of heavy metals and depletion of resources [1].

The paper of scientists $\mathrm{Xu}$ X., Wang C. and Zhou P. takes into account the production of oil and gas from an ecological point of view, included in the problem of ecological routing of vehicles (GVRP) in the distribution of refined oil [15].

In the scientific work of Japanese scientists, polycyclic aromatic hydrocarbons (PAHs) and their halogenated derivatives (GPAG) have been studied in various media. However, analytical problems make it difficult to accurately determine their concentration [12].

The article of Folkers A. from Germany seeks to materialize the social theories of modern times. The article notes how different responses to fossil problems should return and emerge from the material remnants of the past: this applies to biocapitalist projects that seek to "remake" the entropy temporality of fossil remains, as well as environmental justice, which deciphers these remnants as indicators of social call for socio-environmental "redistribution" [3].

The results of the study of Dal Pozzo A., Muratori G., Antonioni G. and Cozzani V. from Italy indicate ample opportunities for optimizing dry acid gas removal systems, in particular with the introduction of multistage systems to support the environmental component of sustainable development [2].

The objective of the study of scientists Naeem M.K., Anwar S, and Nasreen S. from Pakistan is to analyze the economic growth of Pakistan and obtain some alternative sources of production for a sustainable environment [9].

Indonesian authors believe that the use of water in the oil and gas industry requires a comprehensive understanding of the technical problem and the impact on the environment during floods. The study addresses several issues that arise in the process of water injection and offers solutions for efficient and effective project management taking into account environmental aspects [8].

\section{Results}

As a result of mineral extraction, physical, chemical and mechanical disturbances of the soil cover occur. Physical disorders are associated with the transformation of the landscape, deformation of the surface, changes in structure, the development of erosion processes. Changes in the structure and development of erosion processes lead to changes in soil structure, humus content, water holding capacity, gas exchange capacity, density and load holding capacity. Chemical disturbances of the soil are associated with contamination by 
technological wastes and emissions, which affect the $\mathrm{pH}$ value (soil acidity), the ability to cation exchange and the content of nutrients. Mechanical disturbances are caused by processes of transportation of breeds, erosion of dumps, and also dust emissions at performance of technological processes [4].

From the standpoint of ecological economics, the modern economic system is based on the exploitation of the environment. Mineral mining is a classic example of this phenomenon. Extractive resources are estimated primarily at production costs (i.e. costs directly for extraction, transportation) and none of them finds a real economic estimate. Economic activity, built on the principles of ecological economy, in contrast to the "extractive" economy, is based on the concept of natural capital.

The main reasons for the deterioration of the environment in the development of oil and gas fields are:

1) constant pollution of surface waters and deep aquifers with liquid hydrocarbons, highly mineralized waters and harmful salts;

2) high gassiness of the atmosphere during the operation of gas fields and gas storage facilities.

3) frequent cases of open emissions of oil, gas and formation water during the opening of productive formations by wells;

Exploration, prospecting and development of oil and gas fields are the types of work that have the greatest impact on environmental change. Exploration work to detect oil and gas accumulations is a complex and approved set of operations, which includes a certain stage and sequence, using a large number of methods. They are defined by the previously approved Regulations and research practices and include the following stages.

In Fig. 1 the authors schematically present the negative impact on the environmental component of sustainable development of exploration and maintenance work on oil fields.

Stages of exploration:

1. Regional:

- oil and gas forecasting,

- assessment of oil and gas accumulation zones.

2. Exploratory: The purpose is to discover an oil and gas field or new deposits in an unexplored or little-studied part of a section of an already known field. Includes two stages:

- identification and preparation of objects for exploratory drilling, the ultimate goal of which is to determine the location of exploratory wells;

- stage of prospecting, the purpose of which is the discovery of deposits and deposits, carried out by drilling exploratory wells.

3. Exploration: Purpose - the study of already discovered deposits by area, their contouring to determine the size of the field, quantity and quality of oil and gas, the study of the composition and properties of reservoir rocks.

4. Calculation of oil and gas reserves.

These works are carried out by specialists of the drilling company or specialists of service companies, but with due regard to the geological conditions of the field under study. The study of exploration wells includes their experimental operation, which is necessary for the industrial evaluation of the object under study. Hydrodynamic studies of wells at the stage of industrial exploration are carried out in order to determine the initial formation pressure, the nature of fluid filtration, temperature, gas factor, productivity factor and other parameters of deposits. 


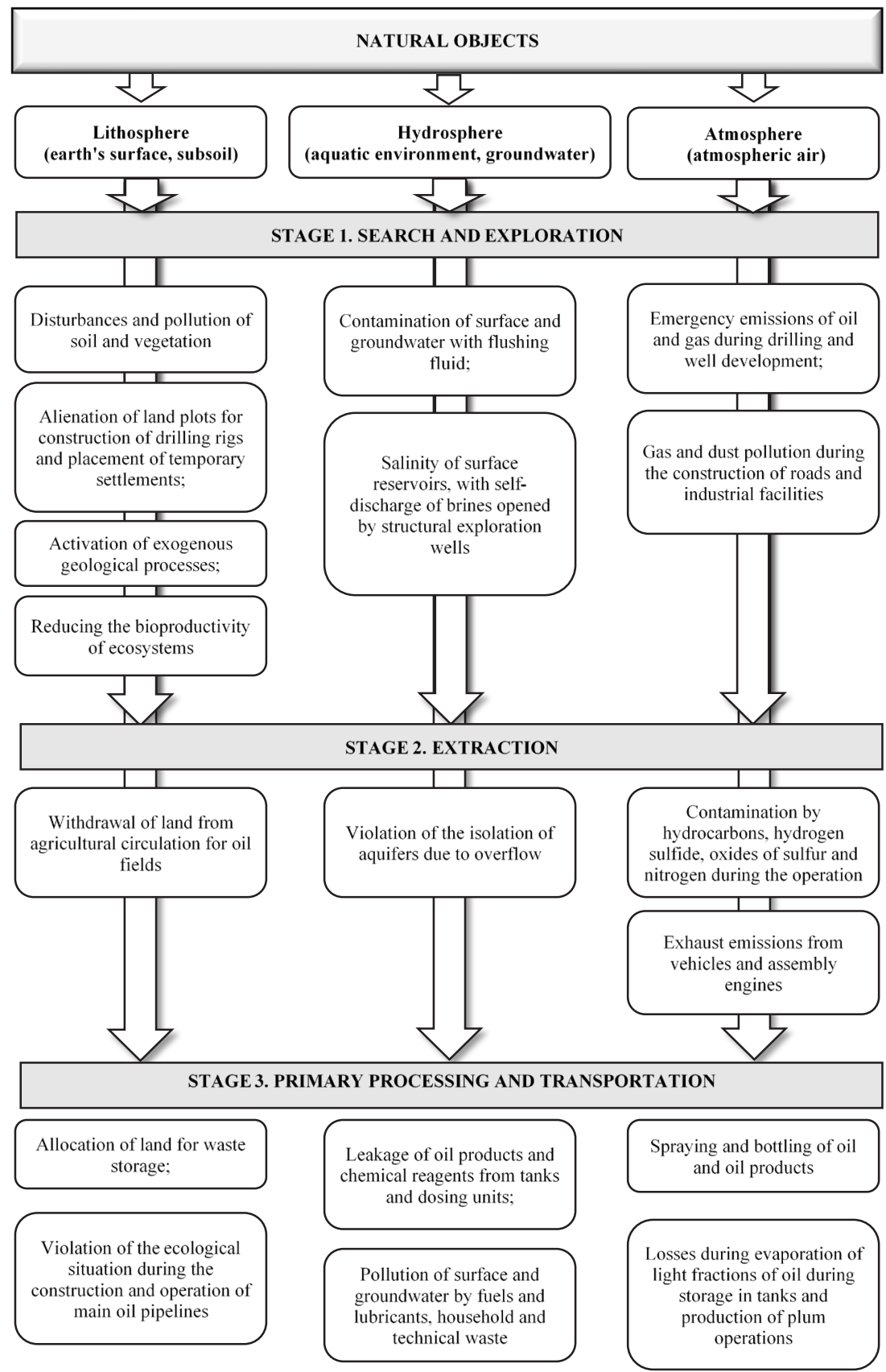

Fig. 1. Negative impact on the environmental component of sustainable development of prospecting and exploitation works on oil fields.

Source: compiled by the authors. 


\section{Conclusions}

In recent decades, man-made environmental problems have become widespread due to the intensive extraction of minerals, which significantly depletes natural resources, in particular in mining regions. Among such problems it is necessary to allocate the following: high degree of technogenic loading and pollution of environment, activation and development of dangerous geological processes, disturbance of hydrogeological conditions, etc.

Environmental problems associated with intensive mining are not limited to low safety, but also related to outdated equipment, non-compliance with technological requirements and standards, the accumulation of industrial waste, the use of environmentally hazardous technologies, ignoring the need to restore disturbed lands. Many companies do not conduct environmental expertise and do not assess the impact on the environment. These typical disturbances are characteristic of the mining industry, which causes significant losses of non-renewable natural resources.

The strategy of competitiveness of mining enterprises should include issues of ensuring the fullest use of extracted minerals, minimizing waste during their extraction and processing; strengthening of control functions, bringing the existing mechanisms in line with international and European requirements of current environmental law, a high level of scientific validity of measures to green production activities.

\section{References}

1. K.W. Chew, S.R. Chia, et al., W.-J. Ong, Environmental Pollution, 278 (2021)

2. A. Dal Pozzo, G. Muratori, G. Antonioni, V. Cozzani, Waste Management, 125, 303-315 (2021)

3. A. Folkers, Time and Society, 30(2), 223-246 (2021)

4. O.I. Kachanovskyi, Environmental sciences, 1(28), 140-143 (2020)

5. I. Kosach, A. Duka, et al., Administratie si Management Public, 35, 139-152 (2020)

6. Y. Lazarenko, O. Garafonova, et al., E3S Web of Conferences, 174 (2020)

7. Z. Li, Y. Zhou, X. Meng, S. Wang, Journal of Petroleum Science and Engineering, 202 (2021)

8. S.K. Lifshits, Y.S. Glyaznetsova, et al., IOP Conf. Ser.: EES, 666(4) (2021)

9. M.K. Naeem, S. Anwar, S. Nasreen, Env. Sci. and Pollut. Research, 28(13),16420-16433 (2021)

10. M.M. Parascanu, M. Kaltschmitt, et al., Sust. Prod. and Consumption, 27, 72-85, (2021)

11. A. Revko, M. Butko, O. Popelo, Comparatie Economic Research. Central and Eastern Europe, 23(2), 21-39 (2020)

12. K. Sei, Q. Wang, et al., Chemosphere, 271 (2021)

13. S. Shkarlet, N. Ivanova, et al., Studies of Applied Economics, 38(4) (2020)

14. R. Tulchinskiy, M. Butko, et al., Polityka Energeyczna - Energy Policy J., 23(3), 93-110 (2020)

15. X. Xu, C. Wang, P. Zhou, International Journal of Production Economics, 235 (2021)

16. Z. Zakaria, S.K. Kamarudin, et al., Renewable and Sustainable Energy Reviews, 144 (2021) 